\title{
Caracterización del profesorado de educación superior que muestra eficacia docente
}

\author{
Characterization of higher education teaching staff showing teaching \\ effectiveness
}

\section{Caracterização de professores de ensino superior mostrando efetividade do ensino}

Raymundo Murrieta Ortega

Benemérito Instituto Normal del Estado, BI Gral. Juan Crisóstomo Bonilla, México murrieta.ortega.r@bine.mx https://orcid.org/0000-0003-4856-9573

\section{Resumen}

El objetivo de la investigación fue identificar las características de los profesores de educación superior que muestran eficacia docente; para ello, se aplicaron encuestas con escala tipo Likert a una muestra de 20 docentes y 480 alumnos de cinco licenciaturas de una escuela normal de la región centro de México. La investigación tuvo un enfoque cuantitativo, con diseño no experimental de tipo transeccional descriptivo, para lo que se tomó una muestra por conveniencia con la participación de profesores con resultados favorables y desfavorables en la evaluación docente en los últimos ciclos escolares. La pregunta de investigación formulada fue la siguiente: ¿cuáles son las características de eficacia docente del profesorado de una escuela normal en México desde la mirada de maestros y estudiantes? Para analizar los resultados se establecieron tres dimensiones: a) personal, b) disciplinar y c) didáctico-pedagógica. Los resultados encontrados demuestran que la edad intermedia de los docentes (41 a 50 años), la experiencia en la docencia (de 16 a 30 años), determinados aspectos personales (disposición a la consulta y el ser humanista), rasgos disciplinares (preparación académica óptima y dominio de la asignatura), así como aspectos didáctico- 


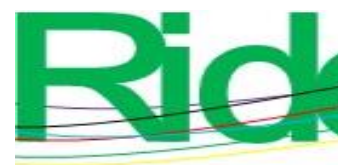

Revista Iberoamericana para la
Investigación y el Desarrollo Educativo
ISSN $2007-7467$

pedagógicos (saber planear, organizar contenidos, crear ambientes de aprendizaje y realizar evaluación congruente) son factores vitales para que logren eficacia docente.

Palabras clave: competencias del docente, enseñanza superior, evaluación del docente, formación de docentes, habilidad pedagógica.

\section{Abstract}

The objective of the research was to identify the characteristics of higher education teachers who show teaching effectiveness; For this, Likert-type scale surveys were applied to a sample of 20 teachers and 480 students from five bachelor's degrees from a normal school in the central region of Mexico. The research has a quantitative approach, with a non-experimental design of a descriptive transectional type, using a convenience sample with the participation of teachers with favorable and unfavorable results in the teacher evaluation in the last school cycles, to answer the research question What Are the characteristics of teaching effectiveness of the teaching staff of a normal school in Mexico from the point of view of teachers and students?

To analyze the results, three dimensions were established: a) personal, b) disciplinary and c) didactic-pedagogical. The results found show that the intermediate age of the teachers (41 to 50 years), their experience in teaching (16 to 30 years), in addition to personal aspects such as willingness to consult and being humanist; disciplinary traits such as having optimal academic preparation and mastery of the subject; as well as didactic-pedagogical aspects such as knowing how to plan, organize content, create learning environments and carry out congruent evaluation, are determining factors for achieving teaching effectiveness.

Keywords: teacher competencies, higher education, teacher evaluation, teacher training, pedagogical ability 


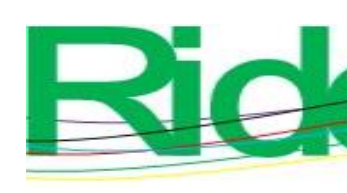

Revista Iberoamericana para la
Investigación y el Desarrollo Educativo
ISSN $2007-7467$

\section{Resumo}

O objetivo da pesquisa foi identificar as características dos professores do ensino superior que apresentam eficácia docente; Para isso, pesquisas em escala do tipo Likert foram aplicadas a uma amostra de 20 professores e 480 alunos de cinco cursos de graduação de uma escola normal na região central do México. A pesquisa tem abordagem quantitativa, com desenho não experimental do tipo transversal descritivo, utilizando uma amostra de conveniência com a participação de professores com resultados favoráveis e desfavoráveis na avaliação de professores nos últimos ciclos escolares, para responder à questão de pesquisa Qual São as características de eficácia docente do corpo docente de uma escola normal no México do ponto de vista de professores e alunos?

Para análise dos resultados, foram estabelecidas três dimensões: a) pessoal, b) disciplinar ec) didático-pedagógica. Os resultados encontrados mostram que a idade intermediária dos professores (41 a 50 anos), sua experiência na docência (16 a 30 anos), além de aspectos pessoais como disponibilidade para consultar e ser humanista; traços disciplinares, como ótima preparação acadêmica e domínio do assunto; assim como os aspectos didáticopedagógicos, como saber planejar, organizar os conteúdos, criar ambientes de aprendizagem e fazer avaliações congruentes, são determinantes para a eficácia do ensino.

Palavras-chave: competências do professor, ensino superior, avaliação de professores, formação de professores, capacidade pedagógica.

Fecha Recepción: Octubre 2020

Fecha Aceptación: Marzo 2021

\section{Introducción}

El tema de la eficacia docente nos lleva a plantearnos los siguientes cuestionamientos: ¿qué hacen los profesores que obtienen resultados sobresalientes en la evaluación docente?, ¿qué tienen de particular en su desempeño académico?, ¿qué los caracteriza y por qué solo algunos demuestran eficacia docente?, ¿cuáles son sus rasgos personales, profesionales y didácticos? Sobre esta temática, Delors (1996) añade otras interrogantes: ¿qué puede esperar razonablemente la sociedad del personal docente?, ¿qué exigencia es realista formular con respecto a él?, ¿quién puede ser un buen profesor? 


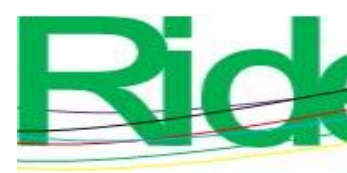

Revista Iberoamericana para la Investigación y el Desarrollo Educativo ISSN 2007 - 7467

Al respecto, en el documento Escuelas y calidad de la enseñanza, publicado por la Organización para la Cooperación y Desarrollo Económico (OCDE) en 1991, específicamente en el capítulo El papel vital de los profesores se destaca que la competencia y la dedicación de los profesores constituyen un requisito previo y vital para el logro de una educación de calidad. En dicho texto, se registra el siguiente planteamiento: ¿qué hacer para preparar profesores eficaces? La OCDE sostiene que la clave está en su formación inicial, por lo que destaca cuatro condiciones: “a) Un correcto equilibrio entre la teoría y la práctica; b) participación de profesores en ejercicio; c) empleo de un adiestramiento basado en la competencia y d) formadores de enseñantes plenamente capacitados" (OCDE, 1991, p. 99).

Por ello, la presente investigación se enfoca en identificar las características de los profesores que muestran eficacia docente en sus intervenciones académicas con estudiantes de licenciatura en cinco programas educativos de una escuela normal que forma a profesores de educación básica en México. La hipótesis formulada es que la eficacia docente de los profesores de la escuela normal se debe a los aspectos personales, disciplinares y didácticopedagógicos.

Una forma común que utilizan las escuelas normales y otras instituciones de educación superior en México para medir la eficacia o ineficacia de los profesores es la evaluación del desempeño docente mediante el uso de Cuestionarios de Evaluación de la Docencia por los Alumnos (CEDA). En el caso de la escuela normal seleccionada, desde el año 2010 existe el Programa Institucional de Evaluación y Seguimiento (PIES), que aplica un instrumento con 27 reactivos para evaluar a cada uno de los docentes frente a grupo, lo cual ha arrojado — según la percepción de los alumnos—resultados satisfactorios, suficientes y deficientes.

García (2013) afirma que los CEDA se implementaron desde 1927 en la Universidad de Purdue (Indiana), por Herman Remmers, a quien se le considera el padre de la evaluación de los profesores por los estudiantes. Sin embargo, vale acotar —como explica García (2013) - que "no existe una definición universal de efectividad docente o de docencia de calidad; esto se debe a que es una actividad compleja que incluye gran variedad de características y de estilos de docencia” (p. 44).

En la escuela normal en estudio, el instrumento para definir la eficacia de los profesores es el denominado Evaluación al desempeño docente, el cual integra un encabezado con el nombre del docente a evaluar y las instrucciones para el llenado del instrumento en escala tipo Likert. El total de reactivos es de 27. La estructura está conformada 


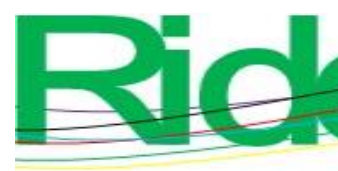

Revista Iberoamericana para la
Investigación y el Desarrollo Educativo
ISSN $2007-7467$

por siete apartados: 1) organización del curso (seis reactivos), 2) dominio de la materia (cinco reactivos), 3) comunicación educativa (tres reactivos), 4) uso de las TIC (tres reactivos), 5) proceso de evaluación (tres reactivos), 6) responsabilidad docente (cuatro reactivos) y 7) eficiencia docente (dos reactivos).

La evaluación docente es realizada de la siguiente manera: al cierre de los periodos escolares (generalmente en enero y junio), los estudiantes evalúan el desempeño de los maestros utilizando dicho instrumento a través de una plataforma digital; posteriormente, los docentes responsables del Programa Institucional de Evaluación y Seguimiento (PIES) procesan los datos y analizan los resultados para finalmente elaborar los informes correspondientes para ser entregados a los directivos y profesores de cada uno de los programas educativos.

Por lo tanto, en las escuelas normales, cuya principal tarea es la de formar docentes para educación básica, se manifiesta una problemática recurrente: contar con algunos profesores que no son expertos en el área disciplinar de formación y que en ocasiones no tienen relación con la docencia; esto último genera que se desconozcan aspectos básicos de la formación de docentes.

En contraparte, existen profesores de excelencia, que reciben el reconocimiento como docentes eficaces a partir de los resultados satisfactorios en las encuestas de evaluación institucional, de ahí que se recojan comentarios como los siguientes: "Es una profesora muy comprometida con su trabajo", "el maestro tiene habilidades didácticas y crea un buen ambiente de aprendizaje", "tiene conocimientos y una calidad humana inigualable", "los aprendizajes del curso fortalecieron mi formación docente", etc.

Por tanto, mediante el seguimiento de los resultados de evaluación a profesores que obtienen resultados satisfactorios de eficacia docente, se establecieron las siguientes interrogantes: 1) ¿con qué formación profesional cuentan y qué experiencia tienen en el magisterio y/o en la escuela normal?, 2) ¿cómo planifican sus sesiones?, 3) ¿qué técnicas introductorias utilizan?, 4) ¿cómo se relacionan con sus alumnos?, 5) ¿cómo establecen ambientes de aprendizaje para generar un proceso de enseñanza-aprendizaje óptimo?, 6) ¿qué habilidades interpersonales manifiestan?, 7) ¿cuáles son sus capacidades para usar las TIC? y 8) ¿cómo evalúan el aprendizaje de sus alumnos? 


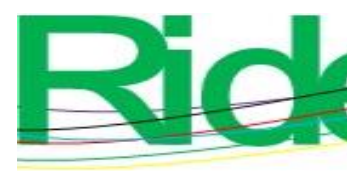

Revista Iberoamericana para la
Investigación y el Desarrollo Educativo
ISSN $2007-7467$

Para lograr lo anterior, se solicitó a la administración escolar de la escuela en estudio un listado de los docentes evaluados durante los últimos ciclos escolares; de ese modo se obtuvo una muestra de diez docentes con resultado satisfactorio y diez con resultado deficiente.

Las preguntas iniciales de la investigación, por tanto, giran en torno a los tres tópicos siguientes:

a) Dimensión disciplinar: ¿Qué formación inicial o disciplinar tienen? y ¿qué experiencia profesional tienen en el magisterio y/o en las escuelas normales?

b) Dimensión personal: ¿Cuáles son sus rasgos personales?, ¿qué habilidades interpersonales manifiestan? y ¿cómo se relacionan con sus alumnos?

c) Dimensión didáctica-pedagógica: ¿Qué acciones didácticas realizan?, ¿cómo planifican sus sesiones?, ¿qué técnicas introductorias utilizan?, ¿cuáles son sus capacidades para usar las TIC? y ¿cómo evalúan el aprendizaje de sus alumnos?, etc.

La pregunta general de investigación fue la siguiente: ¿cuáles son las características generales de los profesores de una escuela normal del centro de México que muestran eficacia docente?

En relación con los antecedentes del tema de estudio, diversos autores han abordado la eficacia docente en el nivel superior. Por ejemplo, Bain (2004) realizó un estudio sistemático durante quince años con 63 profesores universitarios que realizaban prácticas pedagógicas excepcionales. Para lograrlo el autor se preguntó lo siguiente: 1) ¿qué deberían ser capaces de hacer intelectual, física o emocionalmente mis alumnos como resultado de su aprendizaje?, 2) ¿cómo puedo ayudarlos o animarlos de la mejor manera para que desarrollen esas habilidades y los hábitos mentales y emocionales para utilizarlos?, 3) ¿cómo podemos mis estudiantes y yo entender mejor la naturaleza, la calidad y el progreso de su aprendizaje?, y 4) ¿cómo puedo evaluar mis intentos de fomentar ese aprendizaje? Además, afirma que "los mejores profesores planifican hacia atrás: comienzan con los resultados que esperan fomentar" (Bain, 2004, p. 63)

Al respecto, Francis (2006) refiere que "la caracterización del docente excelente o del mejor docente no puede concebirse sin entender que cada docente se construye en un contexto que le hace particular" (p. 34). El estudio permite identificar tres dimensiones en la tarea docente efectiva: la personal, la pedagógica y la disciplinar, las cuales tienen una interacción constante que va modelando la función docente, describiendo que ninguna de las 


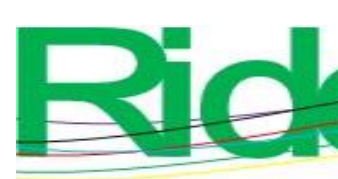

Revista Iberoamericana para la Investigación y el Desarrollo Educativo ISSN $2007-7467$

investigaciones analizadas señala una jerarquía que otorgue primacía a alguna dimensión en particular.

Al respecto, Brombreng, Kirsanov y Longueira (2007) aseguran que la profesionalidad docente se construye sobre dos pilares fundamentales: a) la formación disciplinar, es decir, poseer una sólida preparación científica que le permita acercar al que aprende información cierta y actualizada de la disciplina a su cargo y b) la formación pedagógica, que le posibilitará a cada maestro "realizar una adecuada transposición didáctica, sintetizadora de distintas variables intervinientes en el hecho educativo" (p. 133). Por tanto, afirman que "lo que llamamos profesionalidad docente se logra en el punto de intersección y equilibrio entre la formación disciplinar y la formación pedagógica” (Brombreng et al., 2007, p. 133).

De acuerdo con Sánchez y Domínguez (2008), el perfil del "buen maestro” estaría definido "por las destrezas, conocimiento, preparado, responsable, organizado, comprometido, puntualidad, justo, capacitado, comunicador y empático y por aptitudes inteligente, paciente y flexible” (p. 628). Al mismo tiempo, consideran que la forma más común de evaluación — es decir, el uso de cuestionarios por los alumnos — está limitada; por lo tanto, proponen el modelo de viñetas, “donde al participante, en este caso al docente, se le pudieran presentar situaciones dentro del aula de clases” (Sánchez y Domínguez, 2008, p. $628)$.

Por su parte, García y Medécigo (2014) realizaron una investigación sobre eficacia e ineficacia docente con el objetivo de explorar los criterios que los estudiantes emplean para evaluar la eficacia e ineficacia docente a través de los cuestionarios de evaluación en una universidad pública mexicana. Los resultados indican que las variables o criterios para determinar la eficacia de sus profesores están relacionados con el proceso, presagio y escasamente con los resultados o productos del aprendizaje. Para determinar la ineficacia los estudiantes emplean principalmente criterios de presagio y proceso.

Sobre el tema de la eficacia docente, Patiño (2015) acuña el término docencia efectiva para referirse al "buen" o "auténtico" maestro. Para ellos existe una clara distinción entre un docente "auténtico" y uno "falso". Las principales características del primero son el dominio de la materia que enseña, la actualización permanente de sus conocimientos, el interés por que sus alumnos aprendan, la capacidad de empatía y sensibilidad para captar sus intereses, preocupaciones y motivaciones, su habilidad para comunicarse con ellos efectivamente, la humildad y sencillez para reconocer sus propias deficiencias y poder aprender de manera 


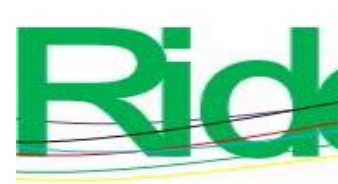

Revista Iberoamericana para la
Investigación y el Desarrollo Educativo
ISSN $2007-7467$

continua de ellos, así como el trato justo, imparcial y democrático. Todo esto se resume en el concepto de veracidad o autenticidad, y las características contrarias constituirán el perfil de un maestro falso o inauténtico.

Patiño (2015) asegura que los docentes efectivos asignan un papel central a las buenas interrogantes, dado que "recurren constantemente al uso de la pregunta para promover la inquietud y la reflexión" (Patiño, 2015, p. 239). Lo anterior coincide con los hallazgos de Bain (2004) — citado por Patiño (2015) — en el sentido de que "los cuestionamientos que dirigen a los estudiantes son provocativos, enigmáticos, novedosos y, en general, buscan provocar un estado de perplejidad que mueve su interés" (p. 239).

En la investigación realizada por Arbesú y Reyes (2015) se describen las características que deben tener los profesores eficaces desde la perspectiva de los estudiantes de educación superior. Se toma como base teórico-metodológica la perspectiva de las representaciones sociales (RS). Entre los principales hallazgos se identifican dos grandes categorías: 1) cualidades profesionales y 2) cualidades personales. En la primera categoría las RS de los estudiantes indicaron que un profesor eficaz es aquel que tiene conocimiento, prepara su clase y se actualiza, sabe explicar, evalúa justamente y tiene buen manejo de grupo. En la segunda — cualidades personales —, los estudiantes comentaron que un profesor eficaz debe tener gusto por la docencia, ser paciente, ético y empático, entre otras más.

Durán-Aponte y Durán-García (2015) afirman que una educación universitaria de calidad implica la trasmisión de saberes unida a la pedagogía para hacerlo, el modelaje de ciertas conductas, la interacción con el estudiante, el desenvolvimiento del profesor dentro y fuera del aula y una serie de aspectos que permiten identificar o diferenciar el desempeño docente de un individuo o de otro. Por tal motivo, realizan una investigación que consistió en adaptar y validar la Escala de Desempeño Docente Institucional, con el propósito de ser utilizada como un medio para evaluar el desempeño docente durante un periodo académico, desde la opinión de los alumnos del primer año universitario. Se realizaron sendos análisis factorial exploratorio y confirmatorio, en los que se obtuvo un modelo explicativo con siete reactivos distribuidos en dos factores denominados: actitud y organización.

En la investigación realizada por Villaroel y Bruna (2017) se propuso un modelo de competencias pedagógicas en el ámbito de la educación superior. El trabajo de investigación responde a un estudio de caso, con enfoque mixto, aplicando instrumentos diversos para recolectar datos en dos universidades chilenas. Entre los resultados sobresale que los "profesores y estudiantes destacaron más el manejo de conocimiento, comunicación y 


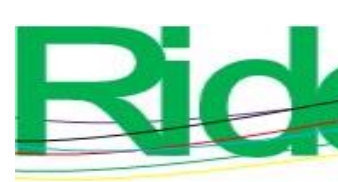

Revista Iberoamericana para la
Investigación y el Desarrollo Educativo
ISSN $2007-7467$

características personales del educador como las principales competencias de un docente de excelencia" (p. 75).

En el trabajo de Herrera, Perendones y Sánchez (2019) se determinaron qué fortalezas personales del profesorado predicen la eficacia docente, con una muestra de 454 docentes de todos los niveles educativos, en dos países (República Dominicana y España). Los resultados indicaron, en primer lugar, relaciones significativas de carácter positivo entre las dos dimensiones de la escala de eficacia docente y las seis fortalezas personales; y, en segundo lugar, el valor predictivo de dos fortalezas personales (humanidad y trascendencia) en lo relativo a la eficacia docente. Se discute la necesidad de incluir en la formación - tanto inicial como permanente del profesorado - el desarrollo de las fortalezas personales, lo que favorece las virtudes humanas.

En relación con el marco teórico, el presente estudio se fundamenta en la concepción de la enseñanza que manifiestan los docentes — también conocida como teorías implícitas. Esta permite analizar procesos internos que el profesor activa básicamente en el momento de planear e intervenir en el aula, aunque también se usa para "conocer el plan que le permite prevenir y valorar la forma en que se desarrollará la clase y evaluará a los estudiantes, y para interpretar y explicar comportamientos o establecer predicciones de la conducta" (Figueroa, 2013, p. 259).

\section{Materiales y métodos}

La presente investigación fue cuantitativa, con un diseño no experimental de tipo transeccional descriptivo, debido a que se pretendió realizar "descripciones comparativas entre grupos o subgrupos de personas" (Hernández, Fernández y Baptista, 2014, p. 156) — en este caso, los profesores que muestran eficacia e ineficacia docente-. Se empleó una muestra por conveniencia, integrada por 10 profesores con altos puntajes (satisfactorio) y 10 con bajos puntajes (deficiente) en la evaluación del desempeño docente. Cada docente encuestado fue evaluado por el grupo al que actualmente impartía clase; por tanto, se utilizó una muestra con grupos intactos conformada por un total de 480 estudiantes de diferentes semestres (ver tabla 1). 
Tabla 1. Docentes y estudiantes participantes

\begin{tabular}{|c|c|c|c|c|c|c|c|c|}
\hline N. $^{\circ}$ & Clave & Sexo & Seudónimo & Estudiantes & Clave & Sexo & Seudónimo & Estudiantes \\
\hline 1 & I-1-D & F & María* & 29 & I-1-S & M & Rigoberto** & 27 \\
\hline 2 & I-2-D & F & Olivia & 16 & I-2-S & F & Paulina & 24 \\
\hline 3 & I-3-D & M & Alberto & 24 & I-3-S & F & Lucía & 24 \\
\hline 4 & I-4-D & M & Pedro & 34 & I-4-S & F & Dolores & 31 \\
\hline 5 & I-5-D & F & Graciela & 16 & I-5-S & F & Tania & 33 \\
\hline 6 & I-6-D & M & Víctor & 18 & I-6-S & F & Lucero & 35 \\
\hline 7 & I-7-D & F & Ivonne & 29 & I-7-S & F & Adelina & 14 \\
\hline 8 & I-8-D & M & Dionisio & 27 & I-8-S & F & Lucrecia & 20 \\
\hline 9 & I-9-D & F & Verónica & 27 & I-9-S & F & Iris & 13 \\
\hline 10 & I-10-D & M & Roque & 10 & I-10-S & F & Elena & 29 \\
\hline & & Total & & 230 & & Total & & 250 \\
\hline
\end{tabular}

Nota: I-1-D (informante 1 deficiente) *María evaluada por 29 estudiantes, I-1-S

(informante 1 satisfactorio) **Rigoberto evaluado por 27 estudiantes, etc.

Fuente: Elaboración propia

Para la recolección de los datos se diseñaron dos cuestionarios: uno para docentes y otro para estudiantes. Mediante el juicio de expertos, se validaron dichos instrumentos; esta actividad es definida como una opinión informada de personas con trayectoria en el tema, que son reconocidas por otros como expertos cualificados, por lo que pueden dar información, evidencia, juicios y valoraciones (Escobar-Pérez y Cuervo-Martínez, 2008).

Para lograr el proceso de validación de los instrumentos se atendieron las siguientes acciones que proponen las autoras Escobar-Pérez y Cuervo-Martínez (2008): datos de experto, plantilla juicio de experto, validación del instrumento y concentrado general de validación por parte de los jueces. Posteriormente, se contactaron a tres expertos en el tema, quienes evaluaron y aportaron sugerencias para la mejora de los cuestionarios. Luego, se realizaron pilotajes de los instrumentos: uno con un grupo de docentes y otro con estudiantes. Las actividades realizadas contribuyeron a la validez y confiabilidad de los instrumentos para recolectar los datos.

El cuestionario de docentes estuvo compuesto por 34 reactivos distribuidos del siguiente modo, a) datos generales (siete reactivos), b) formación profesional (un reactivo en cuadro), c) desempeño docente (veinticinco reactivos con escala tipo Likert y una pregunta abierta). El cuestionario para estudiantes quedó conformado por 29 reactivos divididos en dos rubros: a) datos generales (incluido sexo, semestre y programa educativo) y b) evaluación docente (25 reactivos con escala tipo Likert y una pregunta abierta). 


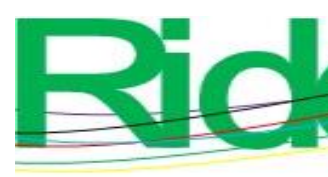

Revista Iberoamericana para la Investigación y el Desarrollo Educativo ISSN 2007 - 7467

Con respecto a los criterios éticos que estuvieron presentes a lo largo de la investigación, se resguardó la identidad de los docentes participantes mediante el uso de seudónimos; al mismo tiempo, la participación de los profesores fue absolutamente libre y voluntaria. Antes de iniciar el proceso de investigación se les expuso abiertamente el objetivo de la investigación y la técnica que sería utilizada.

\section{Resultados}

Los resultados se describen a partir de tres dimensiones: a) disciplinar; b) personal y c) didáctico-pedagógica. (Ver tabla 2).

Tabla 2. Dimensión disciplinar

\begin{tabular}{|c|c|c|}
\hline \multirow{2}{*}{$\begin{array}{l}\text { Unidad de } \\
\text { análisis }\end{array}$} & Autoevaluación del desempeño docente & Evaluación del desempeño docente \\
\hline & Reactivos contestados por docentes & Reactivos contestados por estudiantes \\
\hline $\begin{array}{l}\text { Preparación } \\
\text { profesional }\end{array}$ & $\begin{array}{l}\text { - Mi formación inicial ha contribuido } \\
\text { para desempeñarme eficazmente en } \\
\text { el ejercicio docente. } \\
\text { Mi formación continua (maestría, } \\
\text { doctorado y/o especialización) ha } \\
\text { sido factor importante para } \\
\text { desempeñarme satisfactoriamente } \\
\text { en la docencia. }\end{array}$ & $\begin{array}{l}\text { - La formación inicial del } \\
\text { profesor (licenciatura) } \\
\text { contribuye para su desempeño } \\
\text { eficaz en el ejercicio docente. } \\
\text { - La formación continua } \\
\text { (maestría, doctorado, y/o } \\
\text { especialización) del profesor ha } \\
\text { sido factor para su desempeño } \\
\text { en la docencia. }\end{array}$ \\
\hline $\begin{array}{l}\text { Dominio de } \\
\text { la } \\
\text { asignatura }\end{array}$ & $\begin{array}{l}\text { - Tengo habilidades y el dominio de } \\
\text { mi asignatura para explicar con } \\
\text { claridad los temas. } \\
\text { Me enfoco en que los alumnos } \\
\text { comprendan los temas, } \\
\text { respondiendo con exactitud a sus } \\
\text { preguntas. } \\
\text { - Generalmente formulo preguntas } \\
\text { claras, comprensibles y ajustadas al } \\
\text { alumno y al momento de la clase. }\end{array}$ & $\begin{array}{l}\text { - Tiene habilidades y domina la } \\
\text { asignatura, explica con claridad } \\
\text { los temas. } \\
\text { - Se enfoca en que los alumnos } \\
\text { comprendan los temas, } \\
\text { respondiendo con exactitud a } \\
\text { sus preguntas. } \\
\text { Generalmente formula } \\
\text { preguntas claras, comprensibles } \\
\text { y ajustadas al alumno y al } \\
\text { momento de la clase. }\end{array}$ \\
\hline $\begin{array}{l}\text { Capacidad } \\
\text { para usar las } \\
\text { TIC }\end{array}$ & $\begin{array}{l}\text { - Cuento con las habilidades para } \\
\text { utilizar las TIC en beneficio de los } \\
\text { aprendizajes de los estudiantes. } \\
\text { - El uso que hago de las nuevas } \\
\text { tecnologías fomenta la } \\
\text { participación, la interactividad y la } \\
\text { cooperación entre los alumnos. }\end{array}$ & $\begin{array}{l}\text { - Cuenta con las habilidades para } \\
\text { utilizar las TIC en beneficio de } \\
\text { los aprendizajes de los } \\
\text { estudiantes. } \\
\text { - El uso que hace de las nuevas } \\
\text { tecnologías fomenta la } \\
\text { participación, la interactividad }\end{array}$ \\
\hline
\end{tabular}




\begin{tabular}{|l|l|l|}
\hline & & $\begin{array}{l}\text { y la cooperación entre los } \\
\text { alumnos. }\end{array}$ \\
\hline
\end{tabular}

Fuente: Elaboración propia

\section{Preparación profesional}

Figura 1. Comparativo: preparación profesional

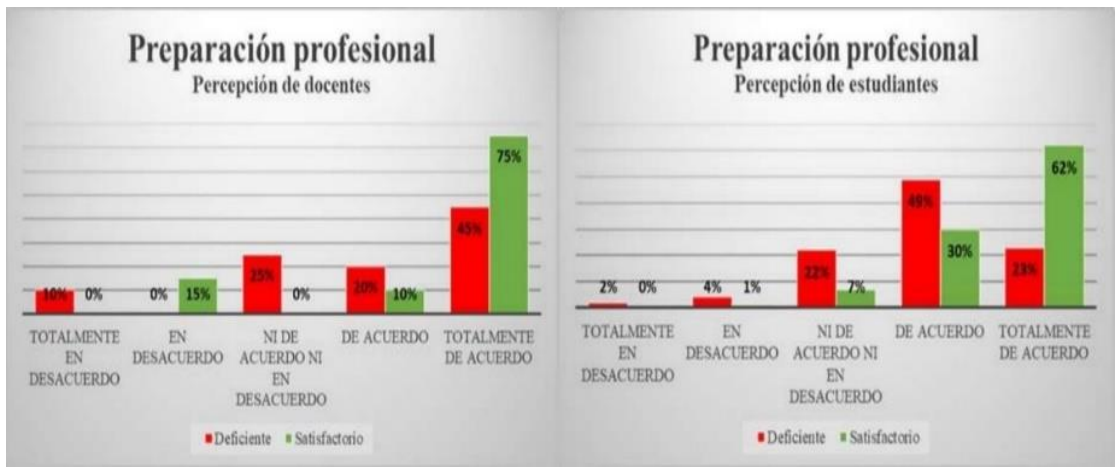

Fuente: Elaboración propia

En la figura 1 se evidencia una balanza favorable para el rubro de docentes satisfactorios desde ambas miradas (profesores y estudiantes), pues consideran que la preparación profesional es un factor fundamental para el ejercicio docente. Los resultados en los profesores deficientes - desde ambas miradas - manifiestan un porcentaje casi igual ( $25 \%$ mirada de docente y $22 \%$ mirada de estudiantes) con respecto a un estado de indecisión sobre si la formación profesional en docentes deficientes les dotó para su desempeño laboral.

\section{Dominio de la asignatura}

Es evidente que los profesores del bloque satisfactorio tienen buena percepción de sí mismos en los tres reactivos integrados: dominio de los temas de la clase, explicación, resolver dudas y formulación de preguntas. Estas percepciones coinciden con las de los estudiantes, quienes manifiestan un alto porcentaje a favor de tales docentes. En contraste, los profesores con resultados deficiente muestran una menor percepción positiva en comparación con el otro bloque. Por su parte, los estudiantes comparten dicha apreciación principalmente en la falta de habilidades para explicar los temas, en la resolución de dudas y en la formulación de preguntas. 

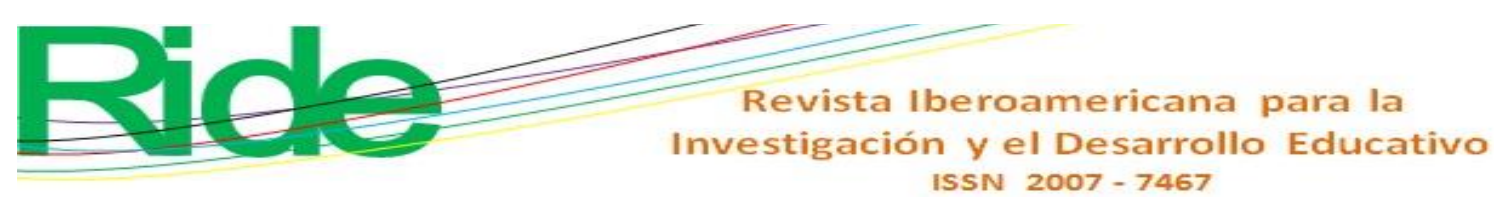

Figura 2. Comparativo: dominio de la asignatura

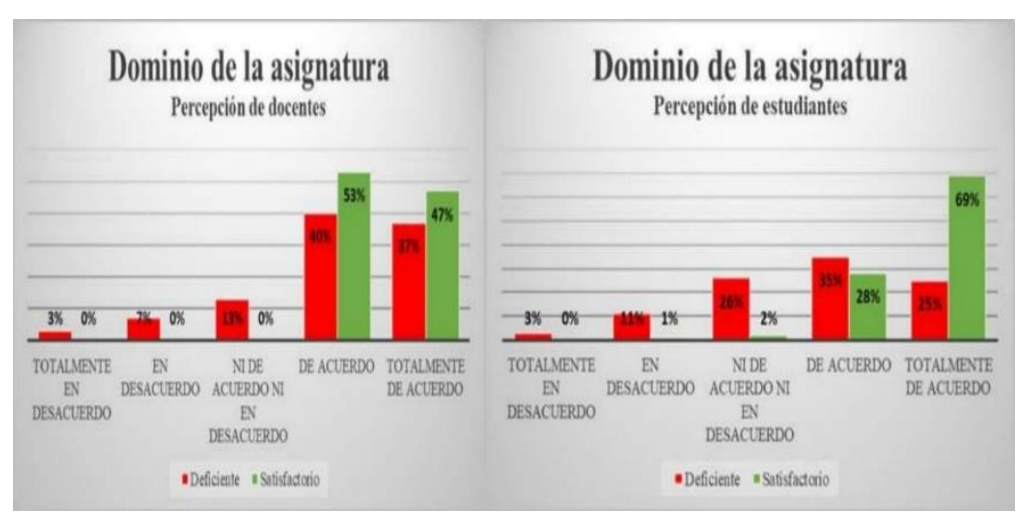

Fuente: Elaboración propia

En la figura 2 se aprecia una inclinación favorable para los docentes del bloque satisfactorio acerca del dominio de la asignatura; por otro lado, desde la mirada de los estudiantes, los docentes satisfactorios obtienen un gratificante porcentaje. Por su parte, los profesores del bloque deficiente logran porcentajes menores en el dominio de la asignatura, pero notorios en el rubro de indecisión desde ambas miradas (13\% profesores y $26 \%$ estudiantes).

\section{Capacidad para usar las TIC}

Los docentes del bloque satisfactorio cuentan con las habilidades para el uso de las TIC, herramienta que fomenta la participación y la cooperación del estudiantado. Al mismo tiempo, desde el bloque deficiente, existen casos de docentes que no utilizan las TIC para el logro de los aprendizajes. Ahora bien, desde la mirada de los estudiantes, se percibe un porcentaje alto en la indecisión en ambos bloques (satisfactorios y deficientes) e incluso una ligera paridad en los aspectos de acuerdo y desacuerdo. (Ver figura 3).

Figura 3. Comparativo: capacidad para usar las TIC

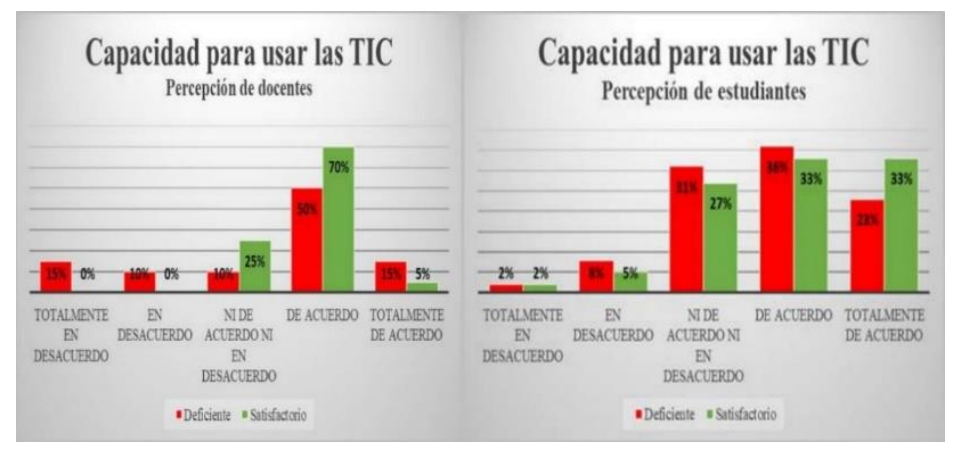

Fuente: Elaboración propia 


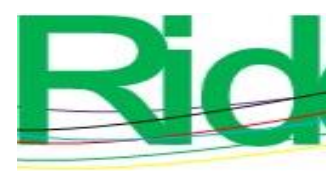

e

Revista Iberoamericana para la Investigación y el Desarrollo Educativo ISSN $2007-7467$

Esta unidad de análisis nos proporciona información valiosa para la reflexión. Desde ambas miradas existe similitud en los resultados de indecisión (profesores $25 \%$ y estudiantes $27 \%$ ) para el bloque de docentes satisfactorios. El porcentaje de $70 \%$ de los docentes satisfactorios también es digno de destacar, aunque existe $5 \%$ de estudiantes que están en desacuerdo con que los docentes satisfactorios tengan capacidades para el uso de las TIC. Por otra parte, desde el bloque deficiente, se nota un porcentaje de $31 \%$ en la indecisión y $10 \%$ que están en desacuerdo sobre la capacidad de los docentes para el uso de las TIC.

Tabla 3. Dimensión personal

\begin{tabular}{|c|c|c|}
\hline \multirow{2}{*}{$\begin{array}{l}\text { Unidad de } \\
\text { análisis }\end{array}$} & Autoevaluación del desempeño docente & Evaluación del desempeño docente \\
\hline & Reactivos contestados por docentes & $\begin{array}{c}\text { Reactivos contestados por } \\
\text { estudiantes }\end{array}$ \\
\hline $\begin{array}{l}\text { Habilidades } \\
\text { interpersonales }\end{array}$ & $\begin{array}{l}\text { - Muestro disposición ante la } \\
\text { consulta de los alumnos dentro y } \\
\text { fuera de la clase. } \\
\text { - Dispongo de habilidades } \\
\text { interpersonales para tratar los } \\
\text { conflictos y darles solución. }\end{array}$ & 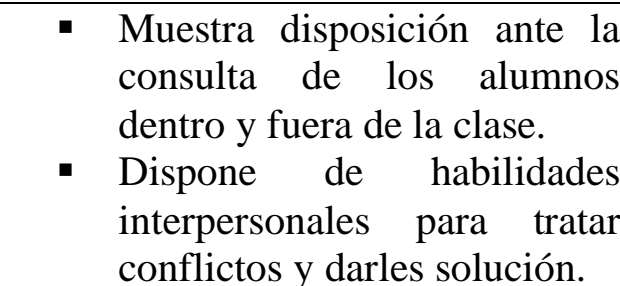 \\
\hline
\end{tabular}

Fuente: Elaboración propia

\section{Habilidades interpersonales}

En referencia a este aspecto, desde la mirada de los docentes existe una paridad, dado que uno de cada bloque se encuentra en la indecisión, y los restantes están de acuerdo con que disponen de habilidades interpersonales para relacionarse con sus alumnos. Desde la mirada de los estudiantes, los resultados demuestran que la balanza se inclina hacia los docentes del bloque satisfactorio, dado que en el bloque de docentes con resultado deficiente se observa un considerable porcentaje en la indecisión y otro en el desacuerdo. 

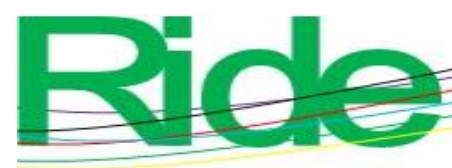

Revista Iberoamericana para la Investigación y el Desarrollo Educativo ISSN $2007-7467$

Figura 4. Comparativo: habilidades interpersonales

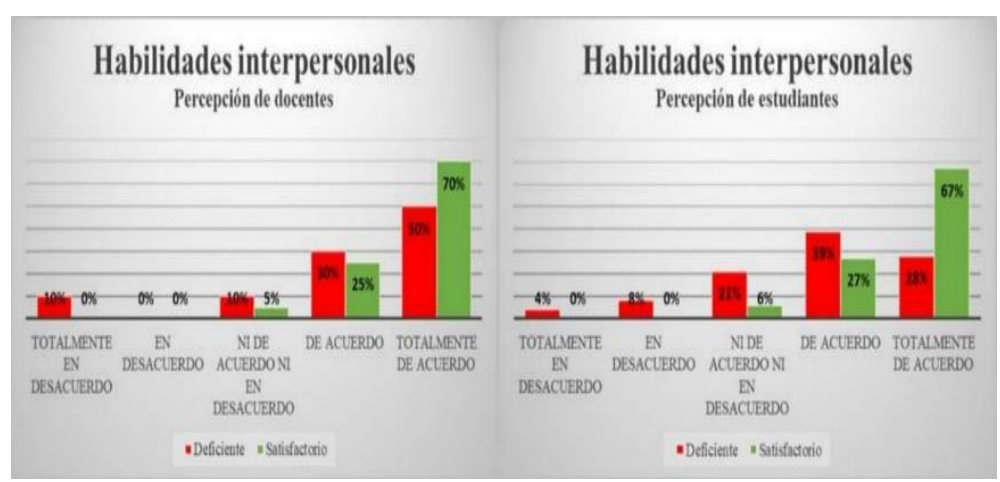

Fuente: Elaboración propia

De acuerdo con lo que se observa en la figura 4 , los docentes satisfactorios se perciben a sí mismos con habilidades interpersonales, dado que alcanzan un porcentaje de $70 \%$ en totalmente de acuerdo y solo $5 \%$ en la indecisión; mientras que los estudiantes comparten esta opinión al sumar $67 \%$ en totalmente de acuerdo y $6 \%$ en la indecisión. Por su parte, en el bloque deficiente, los resultados evidencian un porcentaje favorable menor, aunque un grado notable en la indecisión (docentes $10 \%$, estudiantes $21 \%$ ) y en el desacuerdo (docentes $10 \%$, estudiantes $12 \%$ ). 


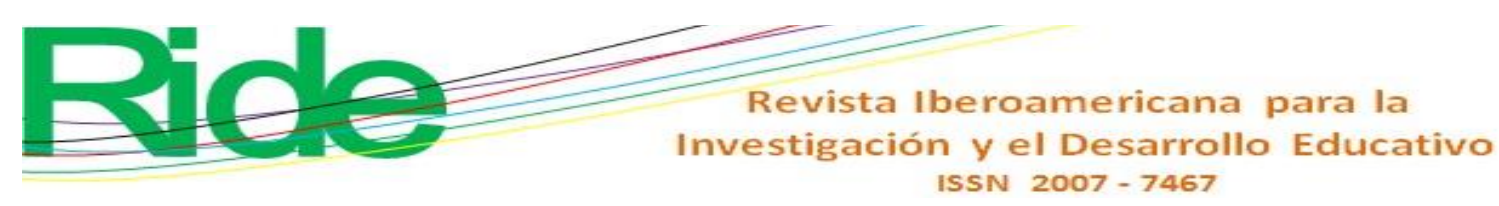

Tabla 4. Dimensión didáctico-pedagógica

\begin{tabular}{|c|c|c|}
\hline \multirow[t]{2}{*}{$\begin{array}{l}\text { Unidad de } \\
\text { análisis }\end{array}$} & $\begin{array}{l}\text { Autoevaluación del desempeño } \\
\text { docente }\end{array}$ & Evaluación del desempeño docente \\
\hline & $\begin{array}{l}\text { Reactivos contestados por } \\
\text { docentes }\end{array}$ & Reactivos contestados por estudiantes \\
\hline Planificación & 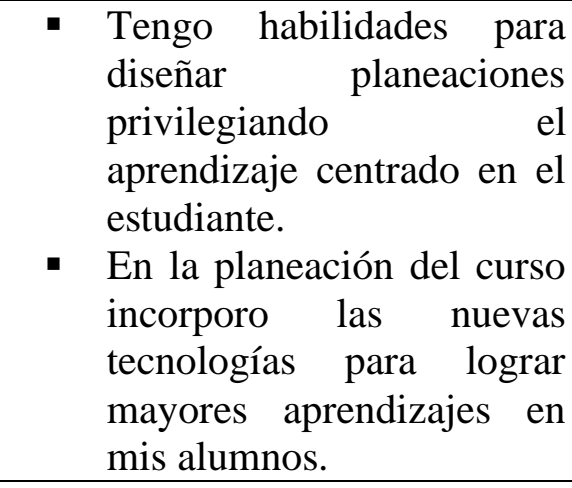 & $\begin{array}{l}\text { - Tiene habilidades para diseñar } \\
\text { planeaciones privilegiando el } \\
\text { aprendizaje centrado en el } \\
\text { estudiante. } \\
\text { - En la planeación del curso } \\
\text { incorpora las nuevas } \\
\text { tecnologías para lograr } \\
\text { mayores aprendizajes en sus } \\
\text { alumnos. }\end{array}$ \\
\hline $\begin{array}{l}\text { Técnicas } \\
\text { introductorias }\end{array}$ & 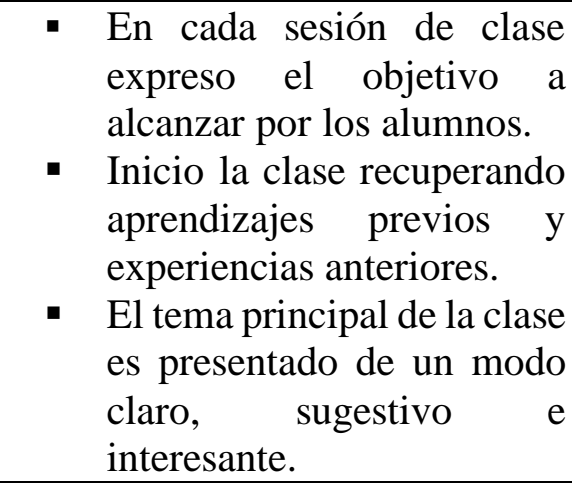 & 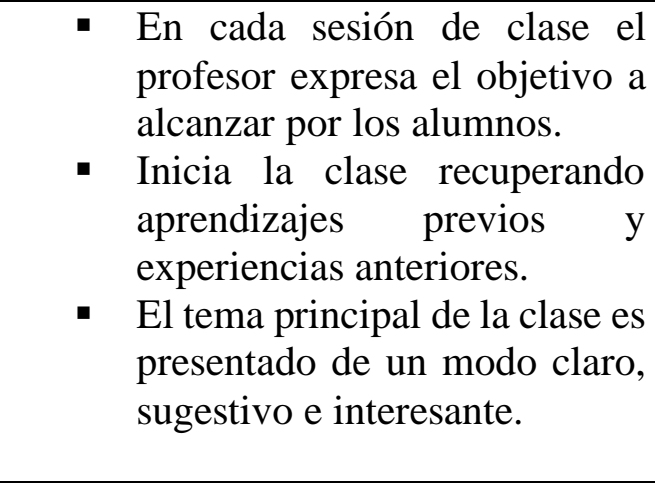 \\
\hline $\begin{array}{l}\text { Secuencia de } \\
\text { contenidos }\end{array}$ & $\begin{array}{l}\text { - Estructuro el trabajo sobre } \\
\text { criterios de orden lógico y } \\
\text { de análisis a través de una } \\
\text { consecución de acciones } \\
\text { que culminen en una } \\
\text { experiencia de aprendizaje. } \\
\text { - Generalmente coinciden } \\
\text { los contenidos de la clase } \\
\text { con lo registrado en la } \\
\text { planeación. }\end{array}$ & $\begin{array}{l}\text { - Estructura el trabajo sobre } \\
\text { criterios de orden lógico y } \\
\text { análisis a través de una } \\
\text { consecución de acciones que } \\
\text { culminen en una experiencia } \\
\text { de aprendizaje. } \\
\text { - Generalmente coinciden los } \\
\text { contenidos de la clase con lo } \\
\text { registrado en la planeación. }\end{array}$ \\
\hline $\begin{array}{l}\text { Proceso } \\
\text { enseñanza - } \\
\text { aprendizaje }\end{array}$ & $\begin{array}{l}\text { - Identifico la consolidación } \\
\text { de conceptos e ideas } \\
\text { fundamentales, antes de } \\
\text { pasar a un episodio nuevo } \\
\text { de aprendizaje. } \\
\text { - Provoco que el estudiante } \\
\text { construya aprendizajes } \\
\text { significativos, creando un } \\
\text { ambiente de aprendizaje } \\
\text { accesible y con un sentido } \\
\text { de autoconfianza. }\end{array}$ & $\begin{array}{l}\text { - Identifica la consolidación de } \\
\text { conceptos e ideas } \\
\text { fundamentales, antes de pasar } \\
\text { a un episodio nuevo de } \\
\text { aprendizaje. } \\
\text { - Provoca que el estudiante } \\
\text { construya aprendizajes } \\
\text { significativos, creando un } \\
\text { ambiente de aprendizaje } \\
\text { accesible y con un sentido de } \\
\text { autoconfianza. }\end{array}$ \\
\hline
\end{tabular}




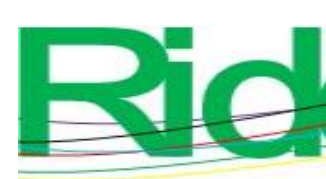

Revista Iberoamericana para la Investigación y el Desarrollo Educativo ISSN $2007-7467$

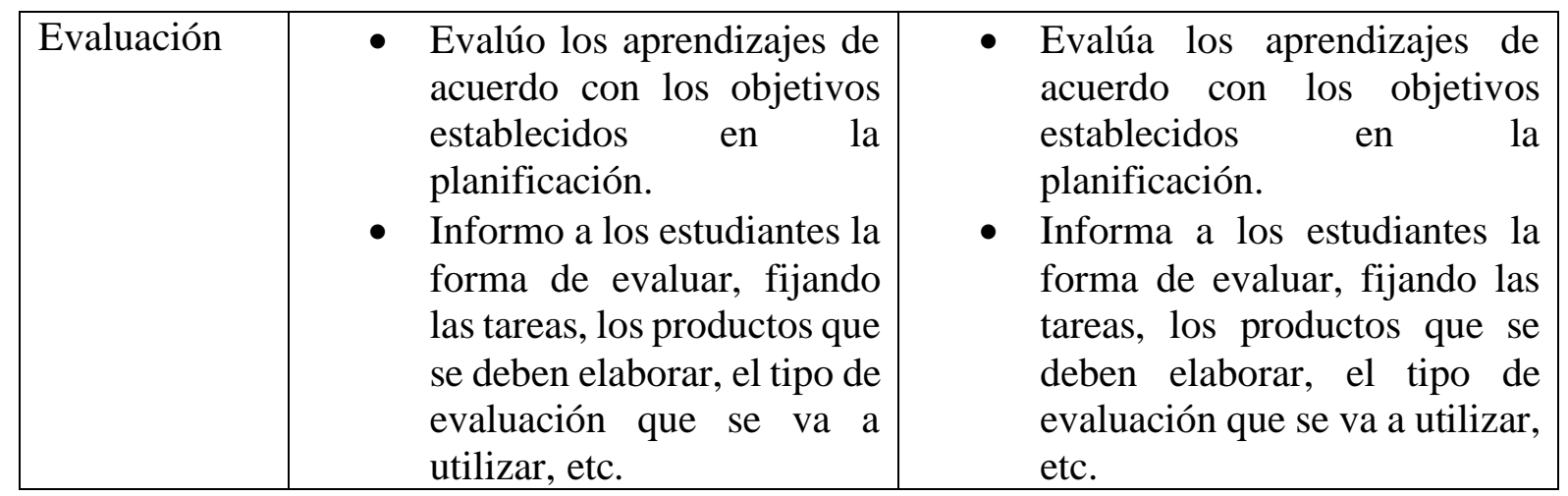

Fuente: Elaboración propia

\section{Planificación}

Figura 5. Comparativo: planificación

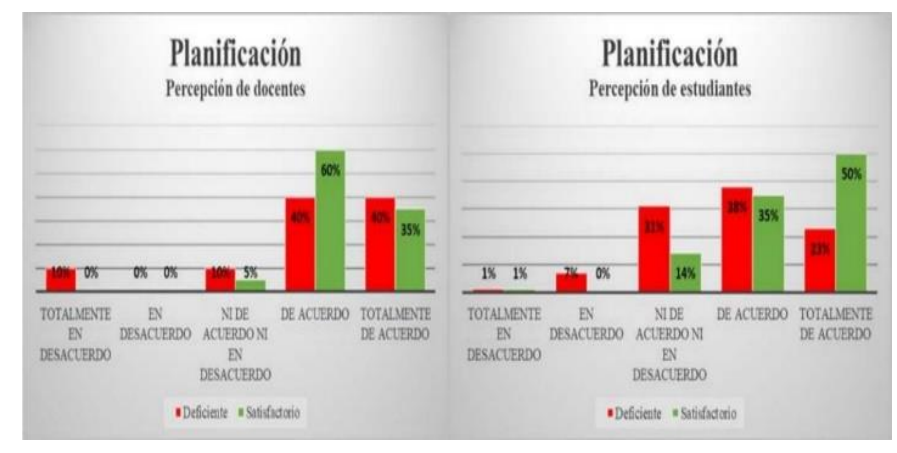

Fuente: Elaboración propia

Con respecto a la unidad de análisis planificación, los resultados denotan, desde ambas miradas, que son los profesores del bloque satisfactorio quienes obtienen mejores porcentajes. Por otro lado, desde el rubro de los docentes del bloque deficiente, los resultados son más bajos, pues resulta evidente que el resto se ubica principalmente en la indecisión (31 $\%$ en estudiantes y $10 \%$ en docentes), así como en el desacuerdo ( $8 \%$ en estudiantes y $10 \%$ en profesores). 


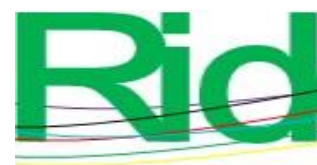

Revista Iberoamericana para la Investigación y el Desarrollo Educativo ISSN $2007-7467$

\section{Técnicas introductorias}

Figura 6. Comparativo: técnicas introductorias

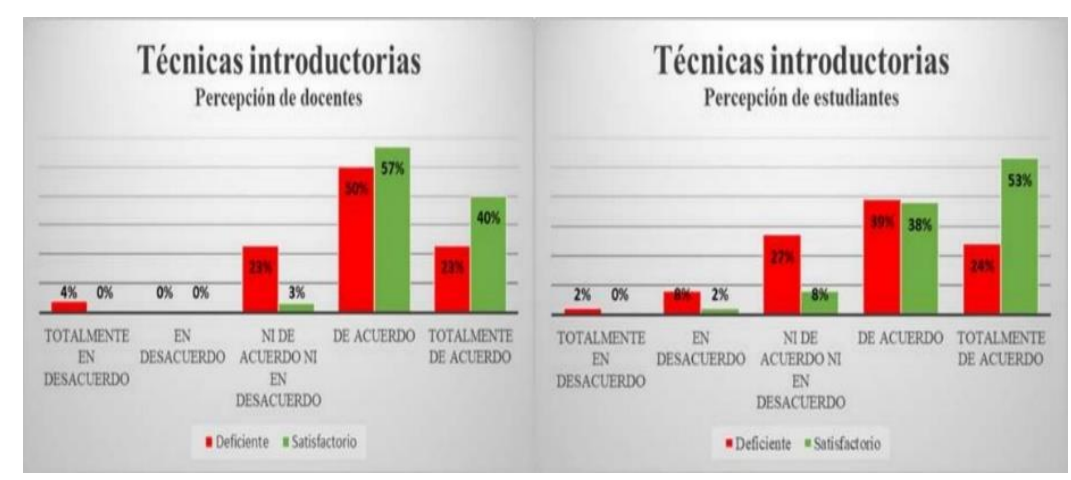

Fuente: Elaboración propia

En la unidad de análisis técnicas introductorias de la figura 6 se percibe, desde ambas miradas, un porcentaje mayor en el bloque satisfactorio. Un aspecto que llama la atención son los niveles de indecisión en el rubro deficiente (27\% desde la mirada de los estudiantes y $23 \%$ de los profesores). También es significativo el porcentaje que está en desacuerdo, principalmente en el rubro deficiente, con un total de $10 \%$ de los estudiantes y $4 \%$ de los docentes.

\section{Ambiente de aprendizaje}

En esta variable los estudiantes tienen una percepción positiva de los docentes con resultado satisfactorio, dado que corroboran la afirmación acerca de que los profesores propician su participación efectiva, mantienen un clima de clase libre de tensiones y aceptan diferentes puntos de vista; en comparación con el bloque deficiente, existe mayor porcentaje en la indecisión y en los aspectos de desacuerdo. 

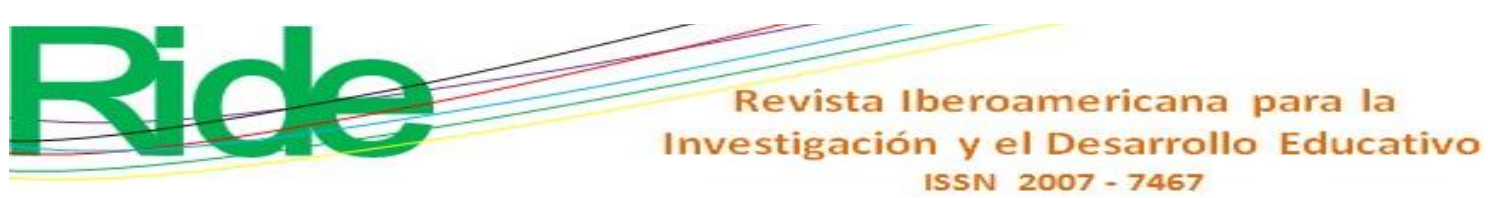

es notorio el porcentaje de $20 \%$ de docentes y $7 \%$ de estudiantes que están en desacuerdo con que realicen una adecuada secuencia de contenidos.

\section{Proceso de enseñanza-aprendizaje}

En este indicador la balanza se inclina para el bloque satisfactorio debido a que los docentes manifiestan una constante percepción positiva de los ítems establecidos en el cuestionario, preferentemente de apropiación de conocimientos por parte de los alumnos antes de continuar con otros temas, como se puede apreciar en la figura 9.

Figura 9. Comparativo: proceso de enseñanza-aprendizaje

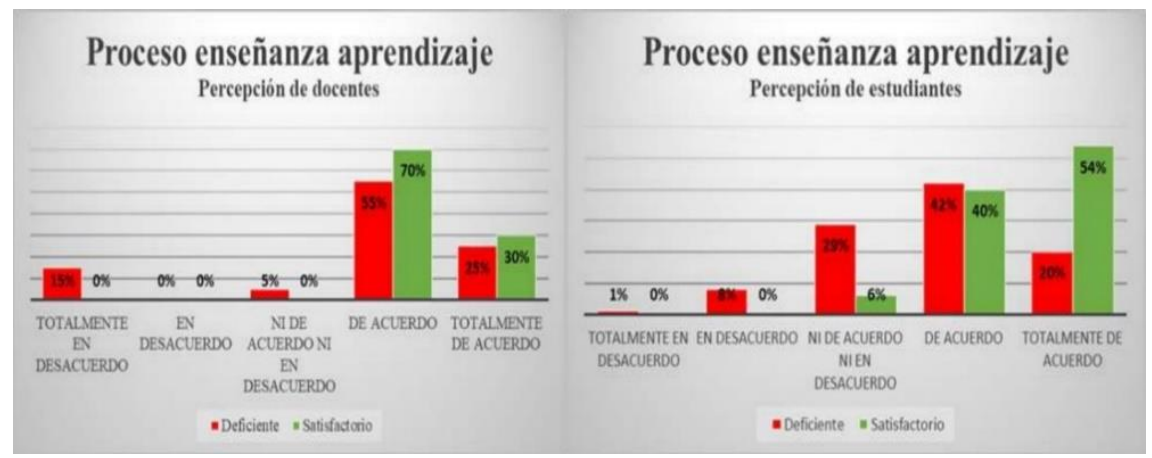

Fuente: Elaboración propia

Los resultados anteriores demuestran un alto porcentaje de aprobación tanto de los mismos profesores como de los estudiantes con respecto a que realizan procesos de enseñanza-aprendizaje óptimos. Solo $6 \%$ de estudiantes se encuentran en la indecisión. Desde el bloque deficiente se identifica un porcentaje menor de aprobación (en comparación con el otro bloque). Asimismo, se registra un alto porcentaje de estudiantes que se encuentran en la indecisión (29\%) y un porcentaje menor (9\%) en el desacuerdo. Mientras que por parte de los docentes se nota un porcentaje mínimo en la indecisión (5\%) y un porcentaje notable en el desacuerdo $(15 \%)$.

\section{Evaluación}

Las opiniones de los estudiantes acerca de la evaluación (figura10) inclinan la balanza hacia los docentes del bloque satisfactorio, específicamente en los acuerdos para la evaluación y en la evaluación de los aprendizajes que establecieron en la planeación; por su parte, para el bloque deficiente disminuye esta apreciación, puesto que en los mismos rubros 

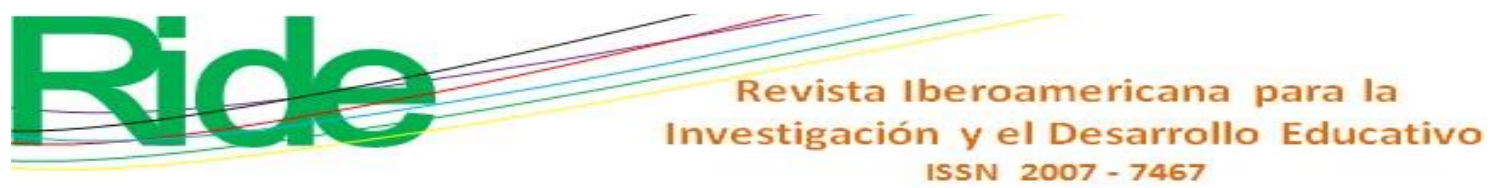

manifiestan un alto porcentaje en la indecisión y se nota un considerable número de casos en desacuerdo.

Figura 10. Comparativo: evaluación

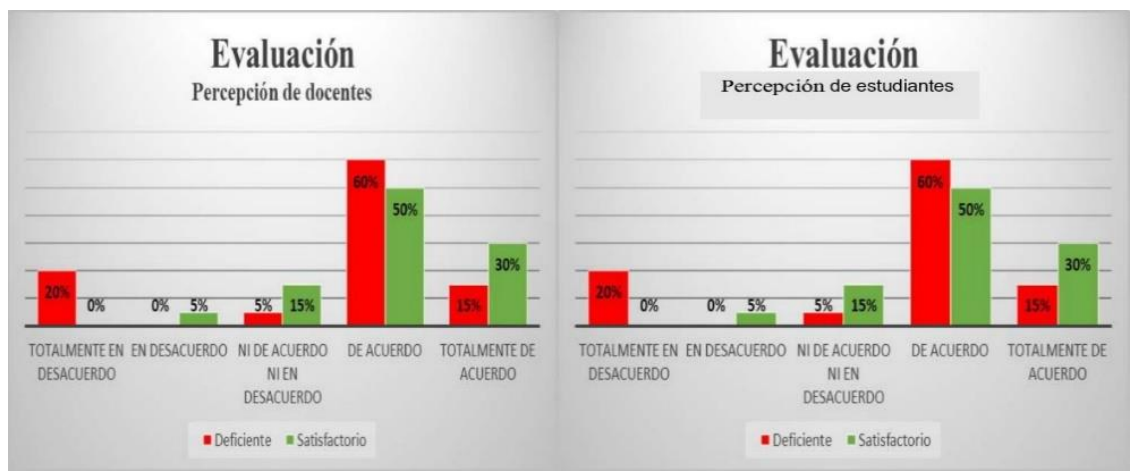

Fuente: Elaboración propia

\section{Discusión de los resultados}

El tema de la eficacia docente ha sido estudiado principalmente en contextos universitarios (Arbesú y Reyes, 2015; Bain, 2004; Brombreng et al., 2007; Durán-Aponte y Durán-García, 2015; Francis, 2006; García y Medécigo, 2014; Herrera et al., 2019; Patiño, 2015; Sánchez y Domínguez, 2008; Villaroel y Bruna 2017), y no tanto en escuelas normales. Por eso, los resultados del presente trabajo resultan significativos y pertinentes para ser contrastados con otras investigaciones, pues de esa forma se puede contribuir a la toma de decisiones y al fortalecimiento de la formación docente.

Los estudiantes y maestros encuestados señalan que los profesores que muestran eficacia docente poseen aspectos disciplinares, personales y didáctico-pedagógicos que influyen en su desempeño frente al grupo. Desde la dimensión disciplinar, se destaca el valor de la preparación profesional (formación inicial y continua) como factor determinante en la eficacia docente.

Al mismo tiempo, ambas miradas coinciden en la importancia de la dimensión personal como elemento primordial en los resultados de la evaluación docente $\mathrm{y}$, en consecuencia, en la eficacia docente. El ámbito personal, por tanto, es considerado como factor relevante para la eficacia docente en los estudios de Francis (2006) y Herrera et al. (2019), por lo que se puede indicar que no es posible separar la personalidad del docente de su método de trabajo. 


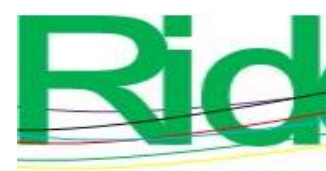

Revista Iberoamericana para la
Investigación y el Desarrollo Educativo
ISSN $2007-7467$

Además, los encuestados ratifican el valor de la dimensión didáctico-pedagógica como parte medular de la intervención de los profesores que muestran eficacia docente, destacando aspectos como la planificación, las técnicas introductorias, los ambientes de aprendizaje, las secuencias de contenidos, el proceso de enseñanza-aprendizaje y la evaluación.

Un aspecto destacado es la planificación, la cual se aborda desde dos ángulos: el primero hace referencia a la habilidad de los docentes para planear, y el otro a la capacidad para incorporar las TIC en la planeación. Con respecto a la habilidad para planear, ambas percepciones (docentes y estudiantes) coinciden en que los profesores que muestran eficacia docente manifiestan un mayor dominio. En cuanto a la incorporación de las TIC en la planeación para lograr aprendizajes en los estudiantes, la percepción de los docentes es positiva (todos están de acuerdo). Para apreciar con mayor claridad las características identificadas en los docentes eficaces estudiados, se presenta la tabla 5:

Tabla 5. Características de los profesores eficaces de la escuela normal en estudio

\begin{tabular}{|c|c|c|}
\hline N. ${ }^{\circ}$ & Dimensión & Características \\
\hline 1 & Disciplinar & $\begin{array}{l}\text { - Tienen una preparación académica óptima. } \\
\text { - Dominan la asignatura. } \\
\text { - Tienen muy buen autoconcepto de su preparación } \\
\text { profesional. } \\
\text { - Saben realizar preguntas provocadoras. }\end{array}$ \\
\hline 2 & Personal & $\begin{array}{l}\text { - Muestran disposición a la consulta de los alumnos. } \\
\text { - Gozan del reconocimiento de los alumnos por su } \\
\text { humanismo. }\end{array}$ \\
\hline 3 & $\begin{array}{l}\text { Didáctico- } \\
\text { pedagógica }\end{array}$ & $\begin{array}{l}\text { - Saben realizar planeaciones. } \\
\text { - Crean un ambiente óptimo para el aprendizaje. } \\
\text { - Establecen un adecuado proceso de enseñanza-aprendizaje. } \\
\text { - Saben organizar los contenidos desde la planeación hasta su } \\
\text { ejecución. } \\
\text { - Saben utilizar las técnicas introductorias. } \\
\text { - Aplican una evaluación congruente. }\end{array}$ \\
\hline
\end{tabular}




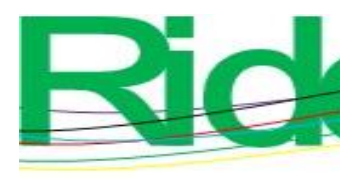

Revista Iberoamericana para la Investigación y el Desarrollo Educativo ISSN 2007 - 7467

Asimismo, la preparación académica se ratifica en el estudio como un hallazgo determinante para obtener resultados satisfactorios en la evaluación docente. En tal sentido, ocho docentes del bloque satisfactorio cuentan con maestría, uno con especialidad y uno con doctorado. De hecho, ellos mismos consideran que la preparación profesional es un factor que influye en el desempeño satisfactorio, mientras que en el caso de los deficientes tres solo tienen licenciatura (incluso uno no tiene dicho grado).

Por otra parte, los profesores eficaces muestran disposición a la consulta de los alumnos, propician su participación, evitan que en la clase se presenten tensiones y aceptan opiniones y puntos de vista diferentes. Esto sirve para promover un ambiente de apertura, libertad y respeto. Además, evalúan los aprendizajes mediante una diversificación de instrumentos que orientan el proceso hacia una evaluación formativa.

Por lo tanto, las características disciplinares de los profesores que muestran eficacia docente en sus intervenciones se describen en seguida. Por ejemplo, cuentan con una formación profesional que reúne los requisitos para desempeñarse de forma suficiente en las IES, todos tienen estudios concluidos de maestría vinculada con la educación (de los diez docentes solo uno no está titulado). Exceptuando tres casos, siete docentes muestran una formación inicial en educación. Tres tienen estudios concluidos de doctorado, aunque solo uno se ha titulado. Por todo lo anterior, se percibe que la formación profesional, enfocada en el área disciplinar de la educación, ha sido factor determinante para que obtengan muy buenos resultados en la evaluación docente.

Asimismo, los docentes eficaces gozan del reconocimiento de sus estudiantes por dominar los temas. Así lo demuestra el reactivo Tiene habilidades y domina la asignatura, explica con claridad los temas, donde $98 \%$ (de 480 estudiantes) están de acuerdo. Además, reciben comentarios alentadores como "realmente es una docente que domina los contenidos correctamente" o "gran docente, siempre está dispuesta a aclarar dudas y escuchar opiniones".

Aunado a lo anterior, los profesores eficaces manifiestan un autoconcepto acertado con respecto a su formación profesional y, desde la mirada de los estudiantes, existe aceptación y aprobación por su preparación. Además, saben formular preguntas, lo que se evidencia en el reactivo Generalmente formula preguntas claras, comprensibles y ajustadas al alumno y al momento de la clase, el cual consiguió un porcentaje favorable. 


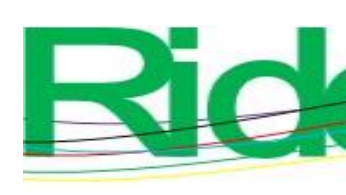

Revista Iberoamericana para la Investigación y el Desarrollo Educativo ISSN $2007-7467$

Por otra parte, con respecto a las características personales, los profesores que obtienen resultados satisfactorios muestran disposición a la consulta de los alumnos. Entre sus cualidades se destaca estar en disposición para atender a los alumnos. El reactivo Muestro disposición ante la consulta de los alumnos dentro y fuera de la clase corrobora dicha afirmación. Sobre este tema, la percepción de los estudiantes (en la opción de acuerdo) se ubica en $96 \%$, mientras que desde la mirada de los docentes (es decir, desde la autopercepción) el mismo criterio se ubica en $100 \%$.

Asimismo, gozan del reconocimiento de los alumnos por su humanismo. En otras palabras, los docentes eficaces se identifican porque disponen de cualidades que los llevan a obtener comentarios favorecedores por parte de sus alumnos, entre los que encontramos: "Es un excelente maestro, sobre todo muy humanista", "el profesor es excelente como persona y como profesionista" y "considero que es una persona muy humana y excelente maestra".

Al mismo tiempo, en el ámbito didáctico-pedagógico, desde ambas miradas (docentes $90 \%$ de autopercepción y estudiantes $94 \%$ de aceptación al estar de acuerdo) los profesores con resultados satisfactorios se destacan porque muestran competencias para el diseño de planeaciones, tal y como se observa en el reactivo Tengo/tiene habilidades para diseñar planeaciones privilegiando el aprendizaje centrado en el estudiante.

Otro elemento favorable tuvo que ver con la capacidad para generar una atmosfera adecuada donde los estudiantes aprendan. De hecho, en todos los momentos de la clase fomentan la participación efectiva y constante del alumno, por lo que evitan crear climas de tensión.

En cuanto a establecer un proceso de enseñanza-aprendizaje adecuado, los profesores sobresalientes logran puntajes de $100 \%$ de aprobación desde la autopercepción (es decir, se saben competentes en su desempeño de aula). Los dos reactivos que conforman este proceso hacen referencia a la "consolidación de conceptos fundamentales" y a la "construcción de aprendizajes significativos". Desde la percepción de los estudiantes, alcanzan más de 90 \%. Las siguientes son afirmaciones de los estudiantes que corroboran los anteriores puntajes: "La maestra es excelente dando clase, ya que como es docente de primaria sabe explicarnos más y con experiencias cómo debemos ser para o en la práctica" y "me parece una maestra ejemplar".

Además, saben organizar los contenidos desde la planeación hasta su ejecución. Es decir, logran que coincidan los contenidos de la clase con lo registrado en la planeación, lo que los lleva a tener una organización perfectamente estructurada para la secuenciación de 


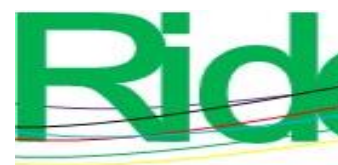

Revista Iberoamericana para la
Investigación y el Desarrollo Educativo
ISSN $2007-7467$

temas en cada una de las clases. Tal afirmación se sustenta en la opinión de un estudiante encuestado: "El profesor es muy bueno, se basa mucho en la planeación, siguiéndola correctamente, sabe explicar bien sus clases y brinda mucho apoyo".

En lo concerniente a las técnicas introductorias, los profesores eficaces en el ejercicio docente las aplican en beneficio de sus estudiantes; por ejemplo, toman en cuenta los aprendizajes previos, la claridad en la presentación del tema y el objetivo a alcanzar. Estas son algunas opiniones de los estudiantes: "Su método de enseñanza es muy bueno, ya que siempre trata de hacer sus clases más dinámicas y llamar la atención de las alumnas", "siempre ha sabido dar la clase de manera didáctica e interesante", y "hace las clases muy dinámicas y de fácil comprensión.

Asimismo, aplican una evaluación congruente con lo planificado, lo que se evidencia en comentarios como "evalúa los aprendizajes de acuerdo a los objetivos establecidos en la planeación”, donde alcanzan $94 \%$ de aceptación por parte de los alumnos y $100 \%$ en la autopercepción.

Finalmente, los alumnos reconocen sus saberes didácticos, lo que se demuestra en opiniones como estas: "El profesor es muy bueno, tiene una alta capacidad para enseñar y transmitir sus conocimientos", "es una docente en toda la extensión de la palabra, de las que realmente se preocupan y ve la forma de que todos aprendan".

\section{Futuras línea de investigación}

Realizar la presente investigación permitió identificar aspectos potencialmente interesantes que detonaron en ideas para el diseño de trabajos académicos complementarios. Por tanto, las futuras líneas de investigación que emergen del presente estudio, se registran a continuación: a) explorar lo referente a las convocatorias de estímulos para el desempeño docente de profesores de educación superior y su efecto en el rendimiento académico, y b) indagar acerca de los instrumentos idóneos para evaluar el desempeño de los docentes de Educación Superior en la enseñanza a distancia.

\section{Agradecimientos}

A los directivos de la escuela normal donde se realizó la investigación por el apoyo recibido y al Consejo de Ciencia y Tecnología del Estado de Puebla (CONCYTEP) por la aportación de recursos financieros. 


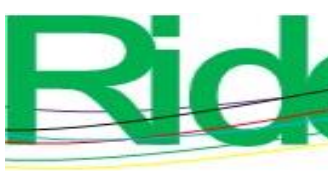

Revista Iberoamericana para la Investigación y el Desarrollo Educativo ISSN $2007-7467$

\section{Referencias}

Arbesú, M. I. y Reyes, L. (noviembre, 2015). La eficacia docente: representaciones sociales de estudiantes universitarios. Observar, Revista electrónica de didáctica de las artes (9), 37-57. Recuperado de https://www.observar.eu/index.php/Observar/article/view/62

Bain, K. (2004). What the Best College Teachers Do. Massachusetts, E.U.A: Harvard University Press.

Brombreg, A., Kirsanov, E. y Longueira, M. (2007). Formación profesional docente. Nuevos enfoques. Argentina: Bonum.

Delors, J. (1996). La educación encierra un tesoro. México: UNESCO.

Durán-Aponte, E. y Durán-García, M. (octubre, 2015). Adaptación y validez de un instrumento para la evaluación de docencia universitaria: escala de desempeño docente institucional (EDDI). Perspectiva Educacional. Formación de Profesores, 54(1), 75-89. Recuperado de https://www.redalyc.org/pdf/3333/333333042006.pdf

Escobar-Pérez, J. y Cuervo-Martínez (junio, 2008). Validez de contenido y juicio de expertos: una aproximación a su utilización. Avances en Medición, 6, 27-36. Recuperado de http://www.humanas.unal.edu.co/psicometria/files/7113/8574/5708/Articulo3_Juici o_de_expertos_27-36.pdf

Figueroa, A. (2013). Una alternativa para la evaluación de la enseñanza en educación superior desde la perspectiva de los profesores. En M. Rueda y F. Díaz-Barriga (Eds.), Evaluación de la docencia. Perspectivas actuales (pp. 255-282). México: Paidós Educador.

Francis, S. (noviembre, 2006). Hacia una caracterización del docente universitario "excelente": una revisión a los aportes de la investigación sobre el desempeño del docente universitario. Revista Educación, 30 (1). Recuperado de https://www.redalyc.org/pdf/440/44030103.pdf

García, J. M. (2013). Las dimensiones de la efectividad docente, validez y confiabilidad de los cuestionarios de evaluación de la docencia: síntesis de investigación internacional. En M. Rueda y F. Díaz-Barriga (Eds.), Evaluación de la docencia. Perspectivas actuales (pp. 41-62). México: Paidós Educador. 


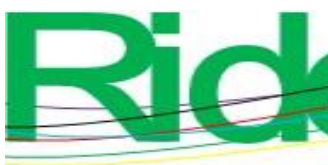

Revista Iberoamericana para la
Investigación y el Desarrollo Educativo
ISSN $2007-7467$

García J. M. y Medécigo, A. (abril, 2014). Los criterios que emplean los estudiantes universitarios para evaluar la in-eficacia docente. Revista Perfiles Educativos, 35(142), 124-139. Recuperado de https://www.redalyc.org/pdf/132/13229888008.pdf

Hernández, R., Fernández, R., y Baptista, P. (2014). Metodología de la investigación. México: McGraw-Hill.

Herrera, L., Perendones, T. M. y Sánchez, L. C. (abril, 2019). Fortalezas personales y eficacia docente. International Journal of Developmental and Educational Psychology, 1(1), 317-324.

Recuperado

de https://revista.infad.eu/index.php/IJODAEP/article/view/1431/1210

Organización para la Cooperación y Desarrollo Económico [OCDE] (1991). Escuelas y calidad de la enseñanza. Informe internacional. España: OCDE.

Patiño, H. (2015). ¿Qué hacen los docentes de excelencia? Claves para la formación humanista en la universidad. México: Universidad Iberoamericana.

Sánchez, S. y Domínguez A. (mayo, 2008). Elaboración de un instrumento de viñetas para evaluar el desempeño docente. Revista Mexicana de Investigación Educativa, 13(37), 625-648. Recuperado de http://www.redalyc.org/pdf/140/14003713.pdf

Villaroel, V. y Bruna, D. (abril, 2017). Competencias pedagógicas que caracterizan a un docente universitario de excelencia: un estudio de caso que incorpora la perspectiva de docentes y estudiantes. Revista Formación Universitaria, 1(4), 75-96. Recuperado de https://www.redalyc.org/pdf/3735/373552294008.pdf 